\title{
Noroviruses in food chain production
}

\author{
Dragoslava Radin \\ Faculty of Agriculture, University of Belgrade, \\ Nemanjina 6, Zemun, Belgrade, Serbia \\ Received: $3^{\text {th }}$ October 2016 . \\ Corresponding author: \\ Faculty of Agriculture, University of Belgrade, \\ Nemanjina 6, Zemun, 11080 Belgrade, Serbia \\ Tel: 0112615315
Fax: 0112199711 \\ E-mail: dradin@agrif.bg.ac.rs
}

\begin{abstract}
Viruses, predominantly noroviruses, are progressively identified as the leading cause of foodborne diseases worldwide. In the Europe Union they have been determined as a main cause of foodborne outbreaks in 2014, while in the United States viruses are responsible for $58 \%$ (5.5 million) of foodborne illnesses annually. Noroviruses, the etiological agent of foodborne gastroenteritis belong to the Caliciviridae family, genus Norovirus which is genetically classified into 6 established geno-groups (GI to GVI). Human noroviruses are icosahedral nonenveloped RNA viruses, approximately 27 to $38 \mathrm{~nm}$ in diameter, and contain single-stranded positive-sense RNA genomes size from 7.4 to $8.3 \mathrm{~kb}$ and 3 open reading frames.

Viruses are transmitted by contaminated food or water, through person-to-person contact, and by cross-contamination from surfaces. Foods at risk includes those which need extensive handling, mostly ready-to-eat foods that do not undergo further processing, and those exposed to environmental contamination, such as seafood and fresh produce. Contamination with human norovirus can happen throughout the entire food production chain: (i) at the primary production (due to fecal polluted water in the harvest area/ irrigation/ water used to dilute pesticide, organic-based fertilizers and potential root uptake of pathogens following internalization); (ii) during harvest (contact with human feces or fecal soiled materials, cross-contamination with equipment and food handlers poor hygiene practice); (iii) at the postharvest stage by inappropriate practices during handling, processing, preparation, storage, distribution (by infected food handlers, spraying with contaminated water, cross-contamination during washing process) and (iv) at the point of sale/consumption (by infected food handlers, cross-contamination with polluted working instruments or surfaces previously contaminated by infected food handlers or food items).

Strategies to reduce human noroviruses in the food chain should, beside good hygiene practice, engage interventions to prevent their adsorption to food/contact surfaces and inactivation on/within the products using successful processing techniques.
\end{abstract}

Keywords: noroviruses, food chain, fresh produce, food handler

\section{INTRODUCTION}

Foodborne viruses are progressively identified as the leading cause of foodborne diseases worldwide. In the Europe Union in 2014, foodborne viruses were, for the first time, identified as the most commonly detected causative agent in the reported foodborne outbreaks, followed by Salmonella, bacterial toxins and Campylobacter [1]. Since 2011, the number of outbreaks caused by viruses has more than doubled (from 525 in 2011 to 1,072 in 2014). In the United States, from estimated 9.4 million foodborne illnesses annually viruses are at the leading position causing 58\% (5.5 million) [2]. From many different viruses responsible for viral gastroenteritis, including adenoviruses, coronaviruses, rotaviruses, parvoviruses and astroviruses, noroviruses are recognized as a main cause of epidemic and sporadic foodborne gastroenteritis, and so represent substantial public health burden [3]. According to the World Health Organization, diarrheal diseases are the leading cause of foodborne disease illnesses - particularly norovirus and Campylobacter spp. It is estimated that one in 10 people in the world fall ill every year due to eating contaminated food. Diarrheal diseases significantly contribute to the global burden of foodborne diseases, causing 230,000 deaths every year [4]. Children aged $<5$ years are at particular risk of foodborne diarrheal diseases, with 220 million illnesses and 96,000 deaths every year. The incidence of norovirus among them is about 4 times higher than for children aged $\geq 5$ years [5]. Some characteristics of norovirus particles go to their benefit, such as they are highly contagious, have a low infectious dose, and are persistent and stable in the environment. The norovirus has an estimated $50 \%$ human infectious dose (HID50) in the range from 18 to 1,015 genome equivalents, though novel estimation is that the HID50 is more similar to those of other RNA viruses (1,320 to 2,800 particles) [6].

Noroviruses belong to the Caliciviridae family, which is composed of five genera, of which genera Norovirus and Sapovirus contain primarily human 
viruses, while the other genera contain animal viruses [7]. Human noroviruses are non-enveloped RNA viruses, approximately 27 to $38 \mathrm{~nm}$ in diameter, have icosahedral shape and contain single-stranded positive-sense RNA genomes ranging in size from 7.4 to $8.3 \mathrm{~kb}$ with 3 open reading frames (ORF1, ORF2, and ORF3). ORF1 encodes a polyprotein that is cleaved into seven nonstructural mature proteins (NS1 to NS7) that are involved in viral replication. ORF2 encodes the major structural protein (VP1) of approximately $60 \mathrm{kDa}$, and ORF3 encodes a minor structural protein (VP2). Noroviruses are genetically classified into 6 recognized genogroups (GI to GVI), while tentative genogroup VII is proposed by Vinjé [8]. GI and GII viruses are responsible for the majority of disease in humans.

\section{TRANSMISSION AND ASSOCIATED FOODS}

Gastroenteritis viruses are typically spread by fecal-oral route. Viruses are transmitted indirectly by contaminated food or water, directly through person-to-person contact, and by crosscontamination from surfaces. Foods at risk includes those which need extensive handling, mostly ready-to-eat foods that do not undergo further processing, and those exposed to environmental contamination, such as seafood and fresh produce. Food and drinking-water may be contaminated at field/primary production by sewage/wastewater in the environment or used for irrigation, or by an infected food-handler [9]. Filter-feeding shellfish is the most common food contaminated at source, but a wide range of different cooked and fresh foods take part in secondary contamination (Table 1).

Generally, contamination of water sources with enteric viruses is a common event to some extent due to the fact that current wastewater treatments do not guarantee complete virus removal [10]. In that manner non-enveloped RNA or DNA enteric viruses persistent in water are becoming environmental contaminants and therefore a public health concern. Water-related diseases are associated not only with drinking and recreational water but also with those used for agricultural practices such as crop irrigation and food processing, which may result in foodborne outbreaks [11]. Foodborne disease outbreaks associated with fresh fruits and vegetables are widespread in the European Union and United States, with norovirus (Table 2.) and Salmonella as the most common pathogens linked to the fresh produce outbreaks. Noroviruses are primarily linked with the consumption of salad in the

Table 1. Examples of confirmed norovirus foodborne outbreaks in US and EU during 2014-2015

\begin{tabular}{|c|c|c|c|c|c|c|}
\hline Year & Food Vehicle & $\begin{array}{c}\text { No. of } \\
\text { outbreaks }\end{array}$ & $\begin{array}{l}\text { No. of } \\
\text { illness }\end{array}$ & $\begin{array}{l}\text { Place of } \\
\text { outbreak }\end{array}$ & Country & Reference \\
\hline \multirow{12}{*}{2014} & $\begin{array}{l}\text { Salad / carrots, cucumber, } \\
\text { green peppers, tomato }\end{array}$ & 1 & 44 & \multirow{3}{*}{ Restaurant } & \multirow{5}{*}{ US } & \multirow{5}{*}{$\begin{array}{c}\text { CDC, } \\
2016 \\
\text { FOOD tool }\end{array}$} \\
\hline & $\begin{array}{c}\text { Guacamole, sour cream, } \\
\text { sauces }\end{array}$ & 2 & 429 & & & \\
\hline & $\begin{array}{c}\text { Macaroni salad, Caesar salad, } \\
\text { breads }\end{array}$ & 2 & 133 & & & \\
\hline & $\begin{array}{l}\text { Potato salad } \\
\text { Green beans }\end{array}$ & 2 & 97 & Banquet Facility & & \\
\hline & Sandwiches & 1 & 40 & Caterer & & \\
\hline & $\begin{array}{c}\text { Crustaceans, shellfish, } \\
\text { mollusks }\end{array}$ & 28 & \multirow{7}{*}{-} & \multirow{7}{*}{-} & \multirow{7}{*}{ EU } & \multirow{7}{*}{$\begin{array}{c}\text { EFSA/ } \\
\text { ECDC2015 }\end{array}$} \\
\hline & Mixed food & 17 & & & & \\
\hline & Vegetables and juices & 11 & & & & \\
\hline & Buffet meals & 5 & & & & \\
\hline & Fruit, berries and juices & 5 & & & & \\
\hline & Bakery products & 3 & & & & \\
\hline & Meat & 3 & & & & \\
\hline \multirow{7}{*}{2015} & Chips, rolls, pastries & 1 & 86 & \multirow{2}{*}{ Banquet Facility } & \multirow{7}{*}{ US } & \multirow{7}{*}{$\begin{array}{c}\text { CDC, } \\
2016 \\
\text { FOOD tool }\end{array}$} \\
\hline & Salad/ Lettuce & 1 & 48 & & & \\
\hline & Cupcakes & 1 & 170 & Hospital & & \\
\hline & Strawberry sauce & 1 & 123 & \multirow[b]{2}{*}{ Banquet Facility } & & \\
\hline & $\begin{array}{c}\text { Cheese and crackers, fruit, } \\
\text { green beans }\end{array}$ & 1 & 170 & & & \\
\hline & Sandwiches & 1 & 54 & $\begin{array}{c}\text { School/college/ } \\
\text { university }\end{array}$ & & \\
\hline & Cake frosting/icing & 1 & 73 & Private home & & \\
\hline
\end{tabular}


US and of berries in the EU [12]. In the production of fresh fruits and vegetables even contaminated water used to dilute pesticides could be a source of human noroviruses, since their infectivity was unaffected when combined with diluted pesticide [13]. Moreover, recent studies have reported internalization and transport of enteric viruses in lettuce plants cultivated hydroponically or during irrigation [14]. These findings indicate possible route of contamination by uptake of virus through the root system and subsequent transport of the virus into edible portions of the plant via vascular tissue.

After viruses attach to the surface of lettuce cell wall they bind by multiple carbohydrate moieties and electrostatic force may play a major role in controlling virus adsorption and enhance virus persistence on the leaf surface. Human norovirus-like particles associate with the surface of Romaine lettuce aggregating in and around the stomata, while in green onions between the cells of the epidermis and cell walls of both the shoots and roots, what suggests that viruses differ in their localization patterns to varieties of fresh produce [15]. Also, there is a need to understand the factors influencing the survival/persistence characteristics of human norovirus on pre-harvest leafy greens to develop proper measures to prevent contamination [16]. For lettuce, as one of the most often implicated fresh vegetable in human norovirus foodborne outbreaks, many theories exist. Some researchers consider that lettuce have the highest adsorption capacity and the most favorable conditions for viral persistence because of the size and the wrinkled texture of its leaves, compared to other smooth, flat surfaces; while others suggest that capacity of lettuce leaf to protect the virus against desiccation is less than green onions or coarse surfaces like ham [17]. In our studies of norovirus GI and GII detection from deli meat, tomato and lettuce similar detection limits of $10 \mathrm{RT}$-PCRU/25 g were obtained while for green onion limit was 1 RT-PCRU/25g [18, 19]. To conclude, viruses can survive on the surface of fresh produce once they have been harvested and remain infectious for several days or for up to 5 weeks during commercial and household storage [20].

One of the well-established vehicles of transmission and principal source of food-borne virus in outbreaks are bivalve shellfish such as oysters, mussels, clams and cockles responsible for large, occasionally international, outbreaks [21]. There are several reasons why shellfish are at risk, but primarily due to their natural habitat and filter-feeding large volumes of water (up to 24 I of water/h) what enables the accumulation and concentration of norovirus particles from polluted water in the digestive glands. Their lifestyle leads to virus concentrations which can be hundreds or even thousands times higher than that in the surrounding water. An FSA-funded study, published in 2011 , determined that $76 \%$ of samples of oysters analyzed at harvest from UK harvesting areas over a two-year period tested positive for norovirus. Another very important safety point is that people in their diet frequently consume uncooked or only with a light heat treatment prepared shellfish which is not sufficient to guarantee virus inactivation. For commercial harvesting, some measures like the depuration process, offer good protection against harmful bacteria such as E.coli, but are not efficient in elimination of viruses from live shellfish.

Table 2. Selected norovirus foodborne outbreaks attributed to fresh produce during the past decade

\begin{tabular}{|c|c|c|c|}
\hline \multirow{2}{*}{ Fresh produce } & No. of illness & Country & Reference \\
\hline \multirow{3}{*}{ Raspberries } & 4 outbreaks/43 & Sweden & Hjertqvist et al. 2006 \\
\cline { 2 - 4 } & 200 & Finland & Maunula et al. 2009 \\
\cline { 2 - 4 } & 13 outbreaks/900 & Finland & Sarvikivi et al. 2012 \\
\cline { 2 - 4 } & 27 outbreaks/913 & EU & EFSA, 2013 \\
\hline Strawberries & 11000 & Germany & Fernard et al. 2014 et al. 2007 \\
\hline Blackberries & 241 & Germany & Makary et al., 2009 \\
\hline Vegetables & 400 & Finland & Schmid et al. 2007 \\
\hline \multirow{2}{*}{ Lettuce } & 182 & Austria & Wadl et al. 2010 \\
\cline { 2 - 4 } & 22 outbreaks/423 & Germany & ECDC, 2010 \\
\cline { 2 - 4 } & 157 & Norway & EFSA, 2013 \\
\hline Leafy greens & 24 outbreaks/657 & EU & ECDC, 2009 \\
\hline Onion & 52 & Finland & Zomer et al. 2010 \\
\hline Tomatoes & 400 & Sweden & Vivancos et al. 2009 \\
\hline Coleslaw & 60 & UK & Yu et al. 2010 \\
\hline Radish & 117 & Korea & ECDC, 2010 \\
\hline Potatoes & 41 & Germany & EFSA, 2013 \\
\hline Bulb/stem veggie & 2 outbreaks/18 & EU & \\
\hline
\end{tabular}




\section{TRANSMISSION AND FOOD HANDLERS}

As previously pointed out, norovirus is highly infectious, this means the organism is likely to be easily spread by food handlers. Infected person can be symptomatic (have had diarrhea and/or vomiting) with a high risk of returning to work while still shedding virus particles or are asymptomatic (infected with no symptoms), but are all the same shedding virus. In both cases, fail to follow the relevant hygiene requirements leads to transmission of viruses and outbreaks. The worst case scenario is if food handlers have an episode of diarrhea or vomiting, which may have resulted in disseminating of virus particles to different commodities, in the workplace. Infected food handlers are the source of $53 \%$ of norovirus foodborne outbreaks and may have contributed even to $82 \%$ of outbreaks [22]. Most foods were likely contaminated during preparation and service and occasionally, the food was contaminated during production and processing. Furthermore, it has been demonstrated that viruses are transferred at different levels from gloved fingertips to produce. Viruses are more easily transferred from fingertips to lettuce as compared to fingertips and soft berries [23]. Undoubtedly, the prime intervention against norovirus is proper hand washing and adequate good hygiene practice.

The other very important source of contamination with viruses is vomiting of infectious person [24]. Recognizing the significance of this source, the latest guidance and vomit-readiness plans, recommend that a $15 \mathrm{~m}$ diameter area should be cordoned off for deep cleaning if norovirus is suspected. Quick action is a critical part of vomit-readiness plans, and although this requirement appears quite important, it will be difficult to implement it in places like aisles of grocery stores or in quick-serve restaurants where closing such wide space would mean closing the facility.

\section{TRANSMISSION AND FOOD CONTACT SURFACES}

Human noroviruses are able to attach to both inert surfaces and vegetal food matrices, and therefore persist for up to 7 days on common foodpreparation surfaces [25]. Essentially all foodborne viruses are shed with feces and therefore easily transmitted from person to person, via food, water and different surfaces (e.g. stainless steel). Moreover, the survival on finger pads is high and its transfer from hand to stainless steel surface and from stainless steel surfaces to vegetable surface could occur relatively easily. A similar example is cross-contamination with equipment. In order to establish pattern of virus transfer during slicing deli meat type bologna, as a model of ready-to-eat foods, the knife blade was artificially contaminated with norovirus particles. For bologna deli, the first two slices contained initial norovirus level, while transfer to slice 3-12 occurred with approx. $50 \%$ reduction per slice [26]. A linear correlation coefficient for knife slicing was partially established between slicing order and level of transferred virus. These data could be used in risk assessment of norovirus cross-contamination during food handling.
Chemical disinfection of food-contact surfaces and rinsing food items with sanitizers is currently applied in order to prevent food-borne outbreaks. Among different household disinfectants, sodium hypochlorite $(3 \%)$ was the most effective for viral inactivation from food contact surfaces [27]. Treatment with hydrogen peroxide (200-1000 ppm), quaternary ammonium compounds (100-2000 ppm), iodine (25-500 ppm), and $10-70 \%$ ethanol exhibited no disinfection effect [28]. Enteric viruses are highly resistant to many biocides commonly used on fresh produce so washing with tap water and chlorine solution (200 ppm) provides on average $1 \mathrm{log}$ reductions in virus titer. Enhanced efficiency in removing a norovirus surrogate from produce (strawberries, raspberries, lettuce and cabbage) is achieved by combining chlorine with surfactants like sodium dodecyl sulfate, Nonidet P-40, Triton $\mathrm{X}-100$, and polysorbates [29].

\section{NOVEL TECHNOLOGIES FOR VIRUS INACTIVATION IN FOODS}

Fresh berries are usually picked, packaged and sold without washing. As for berry products, such as frozen berries and berry purees, a washing step using a sanitizer such as chlorine is applied prior to further processing. Due to the negative impact on sensory quality, thermal processing is usually not applicable for berry products. One of a nonthermal processing technique, high hydrostatic pressure (HHP) processing, has been successfully commercialized for processing a variety of food products, such as fruit jams, orange juice, salsa, guacmole, ready-to-eat meats, oysters, and lobsters since it can greatly retain the original sensory attributes and nutritional qualities of food. Investigation of HHP inactivation of human norovirus on fresh strawberries, blueberries, and raspberries and in their purees, demonstrated that the HHP treatment of $550 \mathrm{MPa}$ for $2 \mathrm{~min}$ at $0{ }^{\circ} \mathrm{C}$ could be a potential non-thermal intervention for virus in berry purees without negatively influence on sensory qualities and physical properties [30].

A chemical treatment of foods, with e.g. chlorine, in order to inactivate viruses is well established. However, due to the possible bad impacts on the environment and production of chlorine by-products, food industry is looking for the potential alternatives. One of the candidates is ozone, a strong oxidizer, like chlorine. Ozone is environmentally friendly and can inactivate a wide range of foodborne pathogens, including viruses, bacteria, and protozoa. It can be effective in the gaseous state or dispersed in water, and do not form residues or by-products. The efficacy of ozone was tested on viruses contaminating seeds intended for production of sprouts [31]. Viruses or inoculated seeds were treated in deionized water containing $6.25 \mathrm{ppm}$ of aqueous ozone with agitation at $22^{\circ} \mathrm{C}$ for $0.5-30$ min. Viral genomes were relatively resistant, with a reduction of 1.50 to $3.00 \mathrm{log}$ genomic copies/g seeds, nevertheless achieved inactivation by aqueous ozone indicates that ozone may be a probable substitute for chlorine treatment.

Other novel intervention strategies with aim 
to reach internalized viral pathogens at the same time as maintaining fresh produce quality are electron beam (E-beam) and gamma radiation. In simple media, a high dose of E-beam treatment was required to completely eliminate the receptor binding ability of human norovirus (35.3 kGy), but was more susceptible to gamma irradiation requiring $22.4 \mathrm{kGy}$ to achieve complete inactivation. In whole strawberries, no virus was detected after $28.7 \mathrm{kGy}$ of E-beam treatment [32]. Human norovirus is highly resistant to ionizing radiation and therefore this technology may not be suitable to eliminate viruses in fresh produce since required doses are much higher than the currently approved levels.

\section{CONCLUSION}

Norovirus is pathogen that attracts a lot of public food safety questions and epidemiological investigations. However, there is a lot of work in front of the food virologists, and despite all gained knowledge virus itself needs more attention. Some specific control measures at industrial level are: hygienic sewage disposal; treatment of drinking-water; management of wastewater used for irrigation; thermal processing; good hygiene practices during production and processing. Recommendation for food service establishment/ household are good personal hygiene (handwashing with soap and water); avoiding to handle food when person is ill, particularly when diarrhea and vomiting are present.

\section{ACKNOWLEDGEMENTS}

The author gratefully acknowledges the funding by Project III 46009 (Ministry of Education, Science and Technological Development of Republic of Serbia).

\section{REFERENCES}

1. EFSA (European Food Safety Authority) and ECDC (European Centre for Disease Prevention and Control). The European Union summary report on trends and sources of zoonoses, zoonotic agents and food-borne outbreaks in 2014. EFSA Journal. 2015; 13(12):4329

2. Scallan E, Hoekstra RM, Angulo FJ, Tauxe RV, Widdowson MA, Roy SL, et al. Foodborne illness acquired in the United States major pathogens. Emerging Infectious Diseases. 2011; 17:7-15.

3. Head MG, Lopman BA. Norovirus in 2016Emesis Aplenty but Clear Signs of Progress. The Journal of Infectious Diseases. 2016; 213(S1):S1-2.

4. World Health Organization (WHO) Burden of foodborne diseases in the South-East Asia Region. WHO Library Cataloguing-in-Publication data. 2016; 1-57.

5. O'Brien SJ, Donaldson AL, Iturriza-Gomara M, Tam CC. Age-Specific incidence rates for norovirus in the community and presenting to primary healthcare facilities in the United Kingdom. Journal of Infectious Diseases. 2016; 213(suppl 1):S15-8.

6. Atmar RL, Opekun AR, Gilger MA, Estes MK, Crawford SE, Neill FH, et al. Determination of the $50 \%$ human infectious dose for Norwalk virus. Journal of Infectious Diseases. 2014; 209:1016-1022.

7. Clark IN, Estes MK, Green KY. Family Caliciviridae. In: King AMQ, Adams MJ, Carstens EB, Lefkowitz EJ. eds. Virus taxonomy: classification and nomenclature of viruses. Ninth report of the International Committee on Taxonomy of Viruses. London. Elsevier Academic Press. 2012: 977-986.

8. Vinjé J. Advances in laboratory methods for detection and typing of norovirus. Journal of Clinical Microbiology. 2015; 53:373-381.

9. Radin D. New trends in food- and waterborne viral outbreaks. Archives of biological sciences. 2014; 66(1):1-9.

10. Blatchley ER. Effects of wastewater disinfection on waterborne bacteria and viruses. Water Environment Research 2007; 79:81-92.

11. Li J. New interventions against human norovirus: progress, opportunities, and challenges. Annual Review of Food Science and Technology. 2012; 3:331-352.

12. Callejon RM, Rodrıguez-Naranjo MI, Ubeda C, Hornedo-Ortega R, Garcia-Parrilla MC, Troncoso AM. Reported foodborne outbreaks due to fresh produce in the United States and European Union: Trends and causes. Foodborne Pathogens and Disease. 2015; 12(1):32-38.

13. Verhaelen $\mathrm{K}$. Persistence of human norovirus in reconstituted pesticides - Pesticide application as a possible source of viruses in fresh produce chains. International Journal of Food Microbiology. 2013; 160:323-328.

14. Wei J. Internalization of Murine Norovirus 1 by Lactuca sativa during irrigation. Applied and Environmental Microbiology. 2011; 77:2508-2512. 
15. DiCaprio E, Purgianto A, Ma Y, Hughes J, Dai X, Li J. Attachment and localization of human norovirus and animal caliciviruses in fresh produce. International Journal of Food Microbiology 2015; 211:101-108.

16. Esseili MA, Gao X, Tegtmeier S, Saif LJ, Wang Q. Abiotic stress and phyllosphere bacteria influence the survival of human norovirus and its surrogates on preharvest leafy greens. Applied and Environmental Microbiology. 2016; 82(1):352-363.

17. Mattison K. Survival of calicivirus. in foods and on surfaces: Experiments with feline calicivirus as a surrogate for norovirus. Journal of Food Protection 2007; 70:500-503.

18. Radin D, D'Souza DH. Simple and rapid detection of human norovirus from produce using SYBR Green I-based real-time RT-PCR. Food and Environmental Virology 2011; 3:121-129.

19. Radin D, D'Souza DH. An efficient and rapid method for detection of human norovirus genogroups I and II from deli meat using realtime RT-PCR. Proceeding "12th International Meat Technology Symposium". Novi Sad. Serbia. 2010; 63-70.

20. Radin D. Significance and molecular detection of noroviruses in fresh produce. In: MendezVilas, A. ed. Microbial pathogens and strategies for combating them: science, technology and education. Badajoz. Formatex Research Center. 2013: 1893-1904.

21. Le Guyader FS, Bon F, DeMedici D, Parnaudeau $S$, Bertone $A$, et al. Detection of multiple noroviruses associated with an international gastroenteritis outbreak linked to oyster consumption. Journal of Clinical Microbiology. 2006; 44:3878-3882.

22. Hall AJ, Curns AT, McDonald LC, Parashar UD, Lopman BA. The rolles of Clostridium difficile and Norovirs among gastroenteritis-associated deaths in the United States, 1999-2007. Clinical Infectious Diseases. 2012; 55:216-223.

23. Verhaelen K, Virus transfer proportions between gloved fingertips, soft berries, and lettuce, and associated health risks. International Journal of Food Microbiology. 2013; 166:419-425.

24. Tung-Thompson G, Libera DA, Koch KL, de los Reyes FL, Jaykus L. Aerosolization of a human norovirus surrogate, bacteriophage $\mathrm{ms} 2$, during simulated vomiting. PLOS ONE. 2015; 10(8):e0134277.

25. Deboosere N. Adhesion of human pathogenic enteric viruses and surrogate viruses to inert and vegetal food surfaces. Food Microbiology. 2012; 32:48-56.

26. Radin D, Velebit B. Transmission of foodborne viruses during food handling. "9th Balkan Congress of Microbiology" Thessaloniki 2015. Acta Microbiologica Hellenica. 60(3):161.

27. Girard M. Attachment of noroviruses to stainless steel and their inactivation, using household disinfectants. J Food Prot. 2010; 73(2):400-404.

28. Ha J, Choi C, Lee H, Ju I, Lee J, Ha S. Efficacy of chemical disinfectant compounds against human norovirus. Food Control. 2016; 59:524529.

29. Predmore A, Li J. Sanitizers by a combination of surfactants and surrogate from fresh vegetables and fruits enhanced removal of a human norovirus. Applied and Environmental Microbiology. 2011; 77:4829-4833.

30. Huang $R$, Ye M, Li X, Ji L, Karwe M, Chen $\mathrm{H}$. Evaluation of high hydrostatic pressure inactivation of human norovirus on strawberries, blueberries, raspberries and in their purees. International Journal of Food Microbiology. 2016; 223:17-24.

31. Wang Q, Markland S, Kniel KE. Inactivation of human norovirus and its surrogates on alfalfa seeds by aqueous ozone. Journal of Food Protection 2015; 78(8):1586-1591.

32. DiCaprio E, Phantkankum N, Culbertson D, Ma $Y$, Hughes $\mathrm{JH}$, Kingsley $D$, et al. Inactivation of human norovirus and Tulane virus in simple media and fresh whole strawberries by ionizing radiation. International Journal of Foo 